\title{
Ongoing Dispersion of Austrian Standard German Front Vowels: A Sociolinguistic Study
}

\author{
By Marjoleine Sloos* \\ Mathea Neijmeijer ${ }^{*}$
}

In Austrian Standard German (ASG), the vowels in the words Beeren and Bären are usually regarded to be merged. Some acoustic studies on ASG also suggest a merger between the vowels as in Miete and Mitte and even between the BEEREN/BÄREN merger and the MIETE vowel. This paper re-investigates these mergers from a sociolinguistic viewpoint and shows that older speakers tend to merge the vowels more than younger speakers. This points towards an ongoing dispersion (or 'unmerger') and we argue that this is a result of accommodation toward Standard German as it is pronounced in Germany.

Keywords: Austrian Standard German, merger/'unmerger', vowel duration.

\section{The Front Unrounded Vowels of Austrian Standard German}

German has been described as a pluricentric language with three clearly distinctive national varieties (namely, Standard German, Austrian Standard German, and Swiss Standard German (see also Clyne (1991); Ammon (1995); Ammon (1996)). The present article focuses on the Austrian variety of Standard German (ASG), which differs from Standard German as spoken in Germany (NSG "Northern Standard German") at the lexical, pragmatic, and grammatical level, as well as in pronunciation. ${ }^{1}$ Here we concentrate on the pronunciation of the non-low front unrounded vowels, which show an interesting pattern of former merger and current reversal. We will show that, previously, four vowels, namely /i: i e: $\varepsilon: /$, were partly merged, but that they are currently undergoing reversal. In the remainder of this paper, we refer to these sounds as the MIETE, MitTE, BEEREN, and BÄREN vowels respectively, conform the formal pronunciation in these words in NSG: Miete [mi:tə] 'rent', Mitte [mitə] 'middle', Beeren [be:Rn] 'berry.PLUR', and Bären [be:Rn] 'bear.PLuR' (cf. the Duden Pronunciation Dictionary Mangold (1994)). By using these labels, we follow a long standing tradition in English sociolinguistics, initiated by Gimson (1962, in Trudgill 2008), which has the advantage of referring to the same lexical sets, based on the standard language, despite different surface and underlying forms in different varieties of the

\footnotetext{
* Interacting Minds Centre, Aarhus University, Denmark \& Fryske Akademy, KNAW (Royal Netherlands Academy of Sciences), The Netherlands.

*University of Groningen, The Netherlands.

${ }^{1}$ As an anonymous reviewer pointed out, different definitions exist of ASG (or Standard Austrian German). In this paper, we use the term in the broadest possible sense: Standard German as spoken in Austria.
} 
language. The vowel system of Standard German, with the vowels under discussion highlighted, are illustrated in Figure 1.

Figure 1. The Vowel Diagram of Standard German, with the Front Unrounded Non-Low Vowels in Bold and the Vowels under Investigation in Black

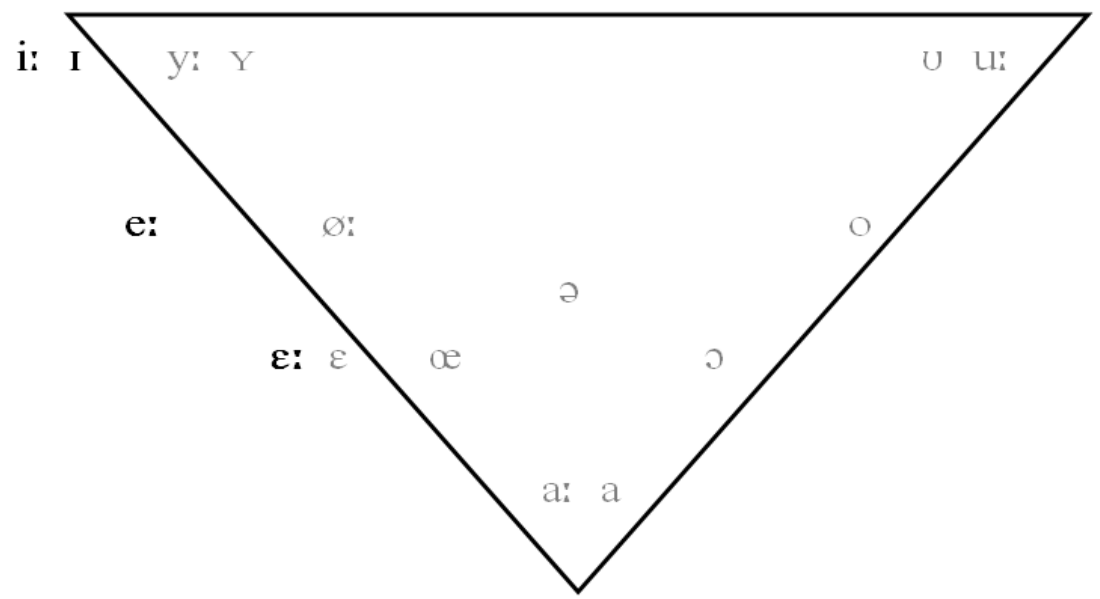

The BEEREN and BÄREN vowels are distinguished by a tense-lax contrast. The MiETE and MITTE vowels in Standard German are distinguished by tenselax opposition, as well as a length opposition. Figure 1 also shows that Standard German has a short $/ \varepsilon /$, but since this vowel is not involved in the mergers, we will not discuss it here any further.

This article builds on previous observations in ASG which involve a merger of the high MIETE and MITTE vowels, as well as a merger of the midhigh BEEREN and BÄREN vowels, and even a possible merger between the high and mid vowels. As for the high vowels, much variation occurs. Do these observations indicate that some speakers merge all four unrounded vowels? Or do speakers vary in the production of the vowels they merge? Does the variation reflect ongoing change, and if so, into which direction: merger or split? And last but not least, what causes merging or 'unmerging' between these vowels? We suspect that the variation is motivated,most likely by accommodation towards NSG. There are several reasons for believing that ongoing vowel change into the direction of NSG is likely to occur in ASG. First, some studies on pragmatic linguistics suggest orientation toward NSG among younger Austrian speakers. In studies on the influence of NSG on ASG through television broadcasting, Muhr (1995, 2003) observes that Austrian speakers are increasingly inclined to accommodate to NSG by a lexical and grammatical shift. Muhr (1995, 2003) attributes this accommodation to Austrian-German language contact through tourism, mass media, and economic co-operation. Similarly, the pronunciation in ASG is likely subject to change, which can be observed in the lowering of the BÄREN vowel, at least in pre-r context as in Bär 'bear' (Sloos 2013a, To appear). Comparable observations have been reported for Swiss Standard German. Under the influence of the media, the pronunciation of Swiss Standard German among younger speakers accommodates toward NSG (Hove 2002, Sloos To appear). 
Given the positive attitude and accommodation at the pragmatic level of younger ASG speakers and the change toward NSG concerning the BÄREN vowel, we hypothesize that the other mergers may be subject to change into the direction of NSG as well. Since Cunha et al. (2013) found that mid and high front vowels in ASG occupy less vowel space than in NSG, we expect an ongoing dispersion of the mid and high front vowels.

The next section provides background information about the mergers. Subsequently, we describe the data, methodology, and statistical analyses, and provides the results. In the last two sections, we discuss the results and presents the conclusion.

\section{A Quadruple Merger?}

This section describes the three mergers of front unrounded vowels in ASG: the BEEREN/BÄREN merger, the MIETE/MITTE merger, and the possibility of a merger between the BEEREN/BÄREN merger and the MIETE vowel. Many studies, including the present one, investigate the formants (frequency peaks of the spectrum). The first formant, F1, is related to the vowel height or openness. A low F1 corresponds with a closed vowel and a high F1 corresponds with an open vowel. The second formant, F2, is related to the vowel backness or the position on the front-back dimension of the highest point of the tongue. A low F2 corresponds with a back vowel and a high F2 corresponds with a front vowel (Figure 2).

Figure 2. Vowel Chart of the International Phonetic Association, with Arrows that Visualize the Relation of F1 with Vowel Openness and F2 with Vowel Backness

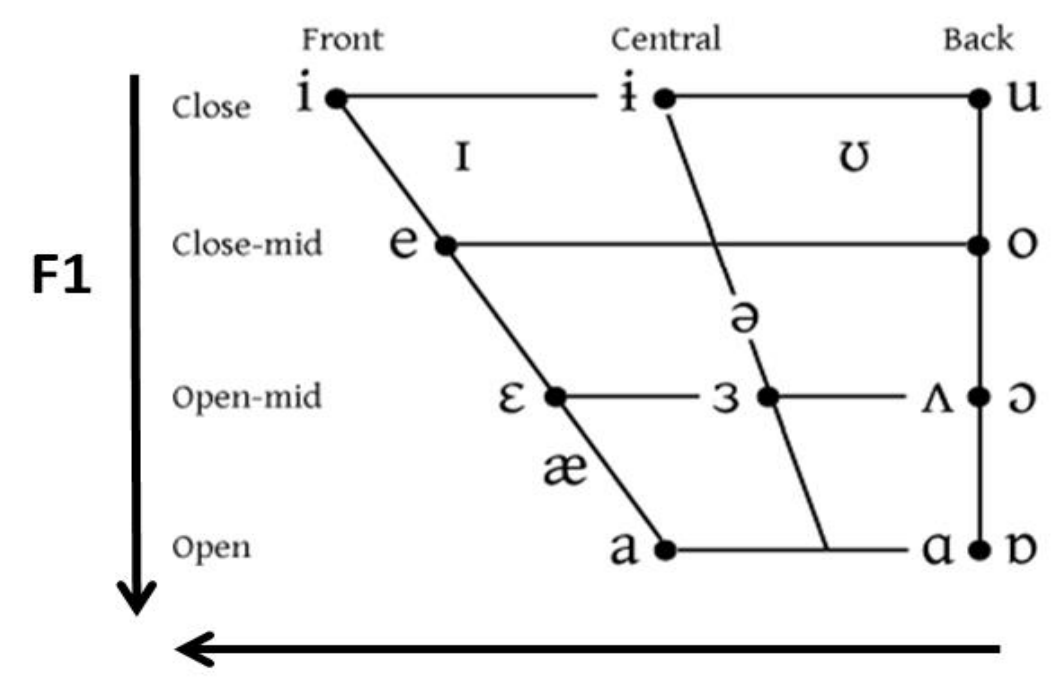




\section{The BEEREN/BÄREN Merger}

It is usually assumed that the BEEREN and the BÄREN vowels, which are phonemically different in NSG, are fully merged in ASG (e.g. Abraham (1971); Wiesinger (1996: 156); Moosmüller (2007); Ehrlich (2010)). This merger between the BEEREN and the BÄREN vowel, in favour of the BEEREN vowel, is actually one of the most prominent differences between NSG and ASG. The Austrian Pronunciation Database and Austrian Dictionary (Muhr, 2007) consistently transcribes the BÄREN vowels in ASG as [e:] but in NSG as $[\varepsilon:]$. The latter transcription corresponds to the pronunciation in formal speech style in NSG (see Stearns \& Voge (1979); Mangold (1994)). The general viewpoint underlying this difference between the ASG and the NSG transcription convention is that stylistic differences (formal vs informal) do not occur in ASG; rather, the BÄREN/BEEREN merger in ASG is observed across the board (in all speech varieties) except in one study: Iivonen (1987). In this experimental investigation into the pronunciation of ASG in Vienna speech, a clear distinction between the BEEREN and the BÄREN vowels is found. It is likely that a laboratory effect which caused hyperarticulation (NSG pronunciation) underlies this clear distinction. However, in spontaneous speech, Sloos (2013a; 2013b, To appear) found that younger Austrian speakers tend to distinguish the BÄREN and the BEEREN vowels more than older speakers, especially in pre-r context. A following rhotic facilitates lowering of the vowel since the rhotic in NSG has the feature [low]. Interestingly, the BÄREN vowel is lowered more than the BEEREN vowel in pre-r context. Sloos (2013a) attributes this differentiation to language contact with NSG. This suggests that the phonological system of ASG is undergoing change and a phonemic distinction is made by some (younger) speakers. The present paper relates this merger reversal to the other reported mergers, to which we will turn next.

\section{The MiETE/MitTE Merger}

In addition to the BEEREN/BÄREN merger, the MIETE and MITTE vowels seem sometimes neutralized, in favour of the MIETE vowel, but evidence is more limited. The first study that points toward a MIETE/MitTE merger is, again, Iivonen (1987). Although no statistical evidence was provided for a full merger, the formants F1 and F2 of the two vowels appeared to be very close. Recently, acoustic overlap of the MIETE and MITTE vowels was reported in a comparative experimental study between German and Austrian speakers Cunha et al. (2013). The results of this study show more acoustic overlap between the MIETE and MiTTE vowels in ASG speakers than in the German speakers. Similarly, Moosmüller (2007) reports acoustic overlap between the MIETE and MiTTE vowels in spontaneous Vienna speech. She investigated F1, F2 and F3, and found that F2 and F3 were in most cases not significantly different, which suggests a merger. Subsequently, Moosmuiller suggests that the MIETE/MITTE vowels are subject to ongoing sound change (Moosmüller, 2008:175) and that 
this may be attributed to social factors (Moosmüller, 2008:176). Even though she does not reveal which social factors may play a role in the suggested sound change, it is clear that it cannot be accommodation toward NSG, because of its clear distinction between the MIETE and MITTE vowels. It is thus likely that the merger is a local (Vienna) feature. But we should also take into account that the number of speakers in Moosmüller's studies is so small $(\mathrm{N}=10)$ that any conclusion regarding sociolinguistic change appears rather impressionistic and premature.

So, evidence exists that the MIETE and MitTE vowels can be merged in ASG, but more investigation is necessary to understand whether or not the variation reflects sound change and the source of the variation (or rather the variety that the speakers accommodate to, viz. the Vienna dialect, NSG, or another variety). In order to do so, more speakers have to be investigated, and in a more systematic way. The present paper therefore investigates spontaneous speech from 29 speakers divided into two age groups.

\section{Merger Between High and Mid Vowels}

In addition to the BEEREN/BÄREN and the MIETE/MITTE mergers, Moosmüller (2008) reports that one speaker in her investigation merged a high vowel (i.e. the MIETE vowel) with a mid-vowel (i.e. the BEEREN vowel). Extremely high pronunciations of both mid vowels (i.e. the BEEREN and the BÄREN vowel) in ASG are also reported in Sloos (2013a). The BÄREN and the BEEREN vowel were compared, such that the speaker-normalized formant measurements of the vowels (F1 and F2) were interpolated on a continuum between /a/ and /i/, where /a/ was quantified as 0 and /i/ was quantified as 100 . The average value for the BÄREN vowel was around 65 and the average value for the BEEREN vowel was 75 in NSG. However, as for ASG, the values were significantly higher, viz. 80 and 84, respectively (Sloos 2013a: 50-51). ${ }^{1}$ During the analysis, it was observed that a considerable number of BEEREN and BÄREN vowels had values even higher than 95. Conversely, the MIETE vowel ranged between 47 and 100. These observations suggest that the mid vowels (viz. the BEEREN and BÄREN vowels) can also merge with the high vowels (viz. the MIETE and MiTTE vowels). We will analyse this merger in more detail in next section.

\section{Approach}

In order to test to what extent the Miete, MitTE, BeEREN, and BÄrEN vowels are neutralized, we investigated spontaneous speech data of ASG. Subsequently, the vowels were speaker-normalized and analysed with speech processing software. Finally, we describe the statistical analysis.

\footnotetext{
${ }^{1}$ This difference between the values of the BEEREN and BÄREN vowels was not statistically significant.
} 


\section{The Data}

The data used in this article come from the corpus Deutsch Heute "German Today", collected by the Institut für deutsche Sprache "Institute for German Language" in Mannheim, Germany (IDS, Project Variation des gesprochenen Deutsch "Variation in spoken German" (Brinckmann et al. 2008)). The material consists of spoken Standard German in different speech styles over the whole German speaking area in Europe. For the present investigation, we used only the biographic interviews, the most spontaneous speech available for both younger and older speakers in the corpus. We selected recordings from all locations in Austria in which older as well as younger speakers have been recorded (Eisenstadt, Linz, Liezen and Leoben, Lienz, and Vienna). ${ }^{1}$ In each of these locations, four younger speakers (aged 18-20) and two older speakers (older than 50) were recorded. Two of the younger speakers were male and two were female, one of the older speakers was male and one was female. All speakers were relatively highly educated. In sum, we analysed 29 speakers (one younger speaker in Linz was not recorded).

For each of these 29 speakers, we manually annotated ten BEEREN, ten MIETE, and ten MitTE vowels. We used all BÄREN vowels, which are the least frequent and some speakers used them fewer than ten times. All selected vowels had primary stress. Since a following rhotic lowers (at least) the mid vowels in German (which has already been extensively analysed in Sloos (2013a)), we avoided this context in the present analysis. Three realizations of $\mathrm{la} / \mathrm{and} / \mathrm{u} /$ per speaker were analysed for the normalization procedure (see next section). The /a/ vowels were all followed by /r/ to arrive at the lowest (i.e. most extreme) realization possible. Similarly, we selected /u/ vowels as much as possible before a high back consonant $/ \mathrm{k} \mathrm{g} \mathrm{x} /$ to arrive at the highest (most extreme) realization possible.

Subsequently, these vowels were analysed with the Praat speech processing software (Boersma \& Weenink, 2010). Formant tracks were automatically computed by using the Burg LPC algorithm. The tracks were manually corrected for if needed (that is, if a visual mismatch between the formant tracks and the formant bands in the spectrogram was observed). The vowels were annotated (without their formant transitions) and then analysed for their duration and their F1, F2, F3, which were measured at $25 \%, 50 \%$ and $75 \%$ of their duration. ${ }^{2}$ During the analysis, it appeared that the vowels under investigation were all true monophthongs; hence it sufficed to use only the temporal midpoint of the vowel for the statistical analysis.

\footnotetext{
${ }^{1}$ We excluded Bludenz, since the local variety belongs to the Alemannic-Swabian dialect group, rather than the Austro-Bavarian dialect group which is spoken in the other locations. The BEEREN-BÄREN merger in Bludenz follows the pattern in Swiss Standard German (Sloos 2013, To appear).

${ }^{2}$ We are grateful to Jos Pacilly (Leiden University) for providing the Praat script.
} 


\section{Speaker Normalization}

Speaker normalization eliminates the effects of physiological differences by individual speakers, but maintains the phonological and sociolinguistic differences. We used the online NORM vowel normalization tool (Kendall \& Thomas, 2007). Since F3 seems to play a role in the studies of Moosmüller (2007, 2008), we selected the Bark normalization procedure (Traunmüller, 1990), which includes F1, F2 and F3. ${ }^{1}$ Another advantage of the Bark normalization procedure is that not all vowels of all speakers are needed for normalization (Kendall \& Thomas, 2007).

Pillai-scores: Degree of Merger

The next step is to obtain a value for the degree of mergers. For that purpose, the data was analysed pair-wise for their Pillai scores, which is interpreted as the measure for the degree of merger (see for instance Hall-Lew (2010) among others). We investigated the following pairs:

- The BEEREN-BÄREN vowels.

- The MitTE-MiETE vowels.

- The MIETE-BEEREN vowels.

- The MitTE-BÄREN vowels.

Statistically, the Pillai score is the result of a MANOVA test on the effect of the lexical set to which the vowels belong on the normalized formants (dependent variables). The outcome, the Pillai score, indicates the difference between the realizations of the two vowel types for each individual speaker. The Pillai score also takes into account the effect of phonological context as a factor of covariance (we choose here the following consonant as context since we suppose in that context most coarticulation is found, analogue to pre-r vowel lowering and raising before a high consonant). The interested reader is referred to Hall-Lew (2010) for further details. The values of the Pillai scores are interpreted as the degree of the distinction between the two vowels by the individual speaker. Significant scores are regarded as a distinction, whereas non-significant scores are regarded as a merger. In addition, we treated the location as a covariant.

\footnotetext{
${ }^{1}$ Where $\mathrm{F}_{i}$ is the value for a given formant $i$, the Bark normalization procedure computes the differences $Z_{3}-Z_{1}, Z_{3}-Z_{2}$, and $Z_{2}-Z_{1}$. Subsequently, vowels can be plotted in which $Z_{3}-Z_{2}$ is treated as the normalized front-back dimension whereas $Z_{3}-Z_{1}$ is treated as the normalized height dimension in the vowel space (Kendall and Thomas, 2007).
} 


\section{Results}

The Pillai scores inform us which speakers distinguish the BEEREN, BÄREN, MiETE, and MitTE vowels. A difference between the two age groups became apparent: younger speakers in general distinguish the vowel pairs more than the older speakers. Table 1 summarizes the results in percentages of how many speakers distinguish the vowels.

Table 1. Percentages Distinctions among Older and Younger Speakers (significance level.05)

\begin{tabular}{|l|c|c|c|c|}
\hline Age & BEEREN-BÄREN & MITTE-BÄREN & MITTE-MIETE & MIETE-BEEREN \\
\hline $18-20(\mathrm{~N}=19)$ & 16 & 37 & 32 & 74 \\
\hline $50+(\mathrm{N}=10)$ & 10 & 20 & 30 & 60 \\
\hline
\end{tabular}

As Table 1 shows, for all pairs, younger speakers made more distinctions than the older speakers; in other words, the younger speakers turned out to disperse the vowels more than the older speakers. Older speakers distinguished the BEEREN and the BÄREN vowels only in $10 \%$ of the cases, whereas among the younger speakers $16 \%$ of these two vowels were distinct. The vowel pairs with a high and a mid vowel turn out to be more distinct, and even more so if pronounced by the younger speakers $(37 \%$ by younger speakers and $20 \%$ by older speakers for the MITTE-BÄREN pair and $74 \%$ by the younger and $60 \%$ by the older speakers in the MIETE-BEEREN pair). The differences are also illustrated in Figure 3.

Figure 3. Bar Plot of the Percentages of Distinction in the Six Vowel Pairs Divided by Age $($ Dark $=$ Younger Speakers and Light $=$ Older Speakers $)$

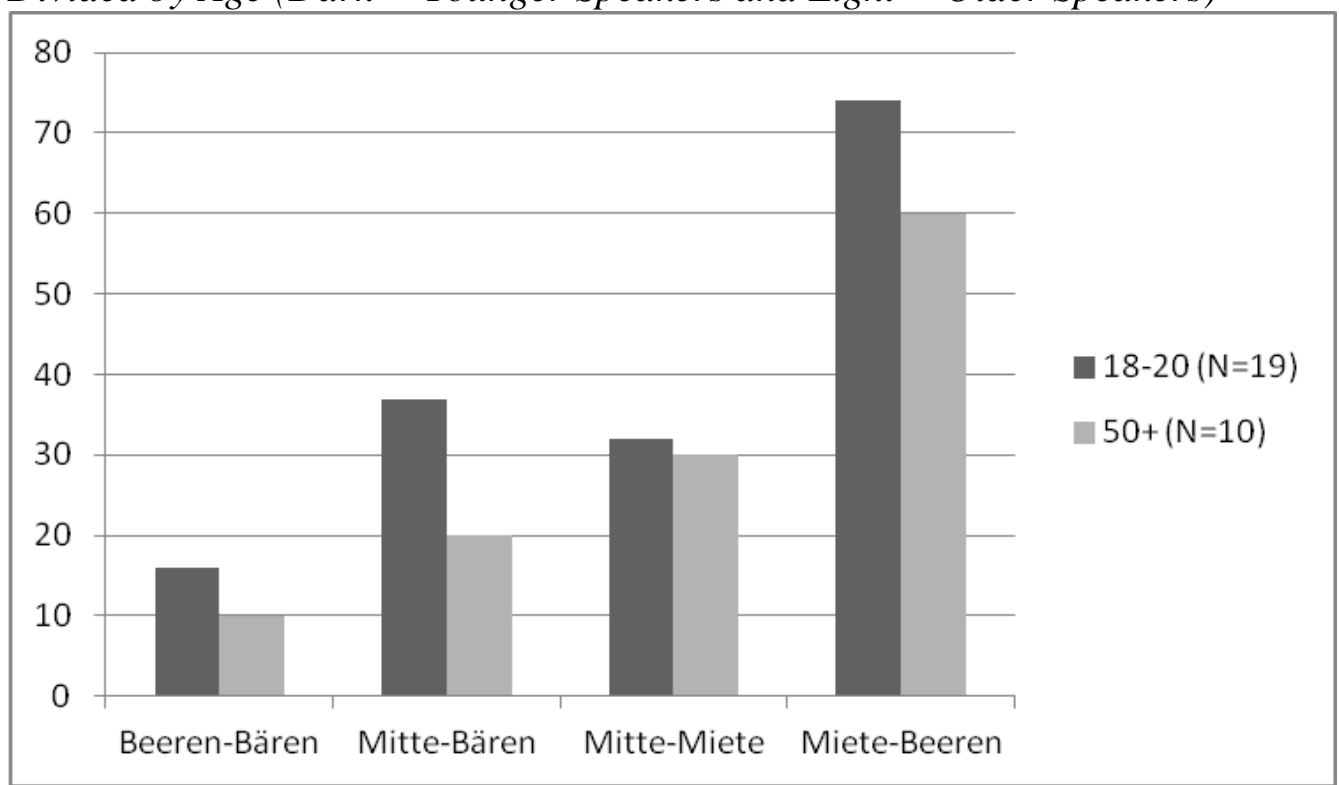

For each of the vowel pairs, all factors turned out to be significant, which shows that younger and older speakers differ in the realization of each vowel pair. The results are summarized in Table 2. 
Table 2. MANCOVA Analysis on the Normalized Formant Measurements

\begin{tabular}{|c|c|c|c|c|c|c|}
\hline \multicolumn{7}{|c|}{ Distinction between the BEEREN and BÄREN vowels } \\
\hline & Df & Pillai & $\begin{array}{c}\text { approx } \\
\text { F }\end{array}$ & $\begin{array}{c}\text { num } \\
\text { Df }\end{array}$ & den Df & $\operatorname{Pr}(>\mathbf{F})$ \\
\hline Vowel type: Age & 3 & 0.091 & 8.04 & 6 & 1008 & $<0.001^{*}$ \\
\hline Phonological context & 17 & 0.159 & 2.56 & 34 & 1008 & $<0.001 *$ \\
\hline Location & 5 & 0.156 & 8.54 & 10 & 1008 & $<0.001^{*}$ \\
\hline \multicolumn{7}{|l|}{ Residuals 504} \\
\hline \multicolumn{7}{|c|}{ Distinction between the BÄREN and MITTE vowels } \\
\hline & Df & Pillai & $\begin{array}{c}\text { approx } \\
\text { F }\end{array}$ & $\begin{array}{c}\text { num } \\
\text { Df }\end{array}$ & den Df & $\operatorname{Pr}(>\mathbf{F})$ \\
\hline Vowel type: Age & 3 & 0.160 & 14.48 & 6 & 1000 & $<0.001 *$ \\
\hline Phonological context & 16 & 0.144 & 2.42 & 32 & 1000 & $<0.001 *$ \\
\hline Location & 5 & 0.145 & 7.81 & 10 & 1000 & $<0.001^{*}$ \\
\hline \multicolumn{7}{|l|}{ Residuals 500} \\
\hline \multicolumn{7}{|c|}{ Distinction between the BEEREN and MIETE vowels } \\
\hline & Df & Pillai & $\begin{array}{c}\text { approx } \\
\text { F }\end{array}$ & $\underset{\text { Df }}{\text { num }}$ & den Df & $\operatorname{Pr}(>\mathbf{F})$ \\
\hline Vowel type: Age & 3 & 0.316 & 35.23 & 6 & 1128 & $<0.001^{*}$ \\
\hline Phonological context & 20 & 0.313 & 5.25 & 40 & 1128 & $<0.001^{*}$ \\
\hline Location & 5 & 0.107 & 6.37 & 10 & 1128 & $<0.001^{*}$ \\
\hline \multicolumn{7}{|l|}{ Residuals 564} \\
\hline \multicolumn{7}{|c|}{ Distinction between the MIETE and MITTE vowels } \\
\hline & Df & Pillai & $\begin{array}{c}\text { approx } \\
\text { F }\end{array}$ & $\begin{array}{c}\text { num } \\
\text { Df }\end{array}$ & den Df & $\operatorname{Pr}(>\mathbf{F})$ \\
\hline Vowel type: Age & 3 & 0.176 & 17.97 & 6 & 1116 & $<0.001^{*}$ \\
\hline Phonological context & 21 & 0.144 & 2.06 & 42 & 1116 & $<0.001^{*}$ \\
\hline Location & 5 & 0.108 & 6.40 & 10 & 1116 & $<0.001^{*}$ \\
\hline
\end{tabular}

The interaction between vowel type and age results indicate that the vowels undergo change (since the younger speakers have significantly different realizations than the older speakers). The location of the speakers also affected the data, suggesting much variation depending on the location. The phonological context, that is, the sound following the vowels, influenced the data as well. Since our data is limited and we cannot control this factor (because the data are from a corpus), we leave further (experimental) investigation of the phonological context to the future and concentrate here on the change in progress for the remainder of this article. To show the direction of the change, we plotted the aggregated normalized vowels (average for all speakers within each of the two age groups) in a vowel diagram (see Figure 4). 
Figure 4. The Speaker-Normalized Aggregated Means of the BEEREN, BÄREN, MIETE, and MITTE Vowels for Younger (Upper Plot) and Older (Lower Plot) Speakers

Vowel Plot for Older Speakers

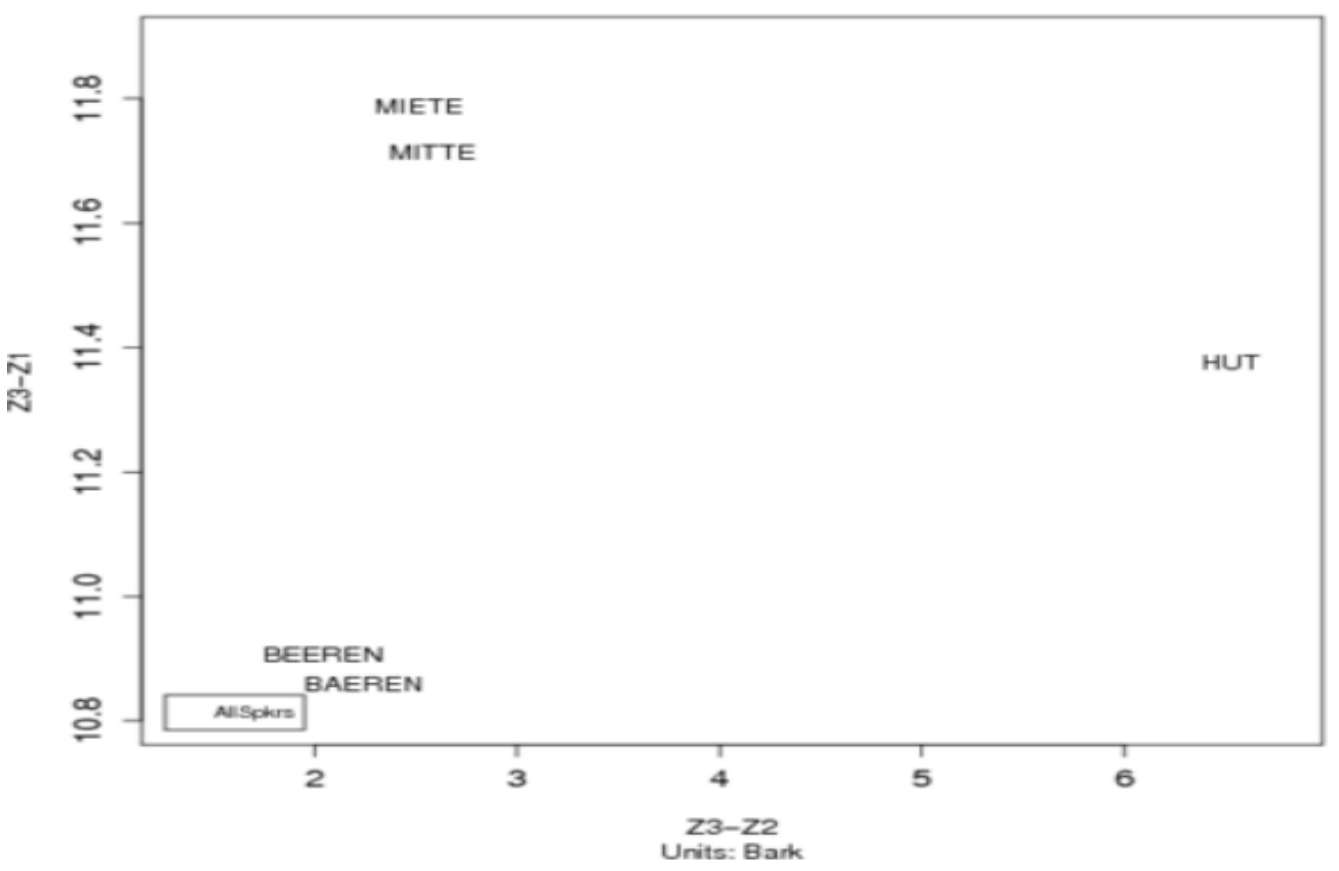

Vowel Plot for Younger Speakers

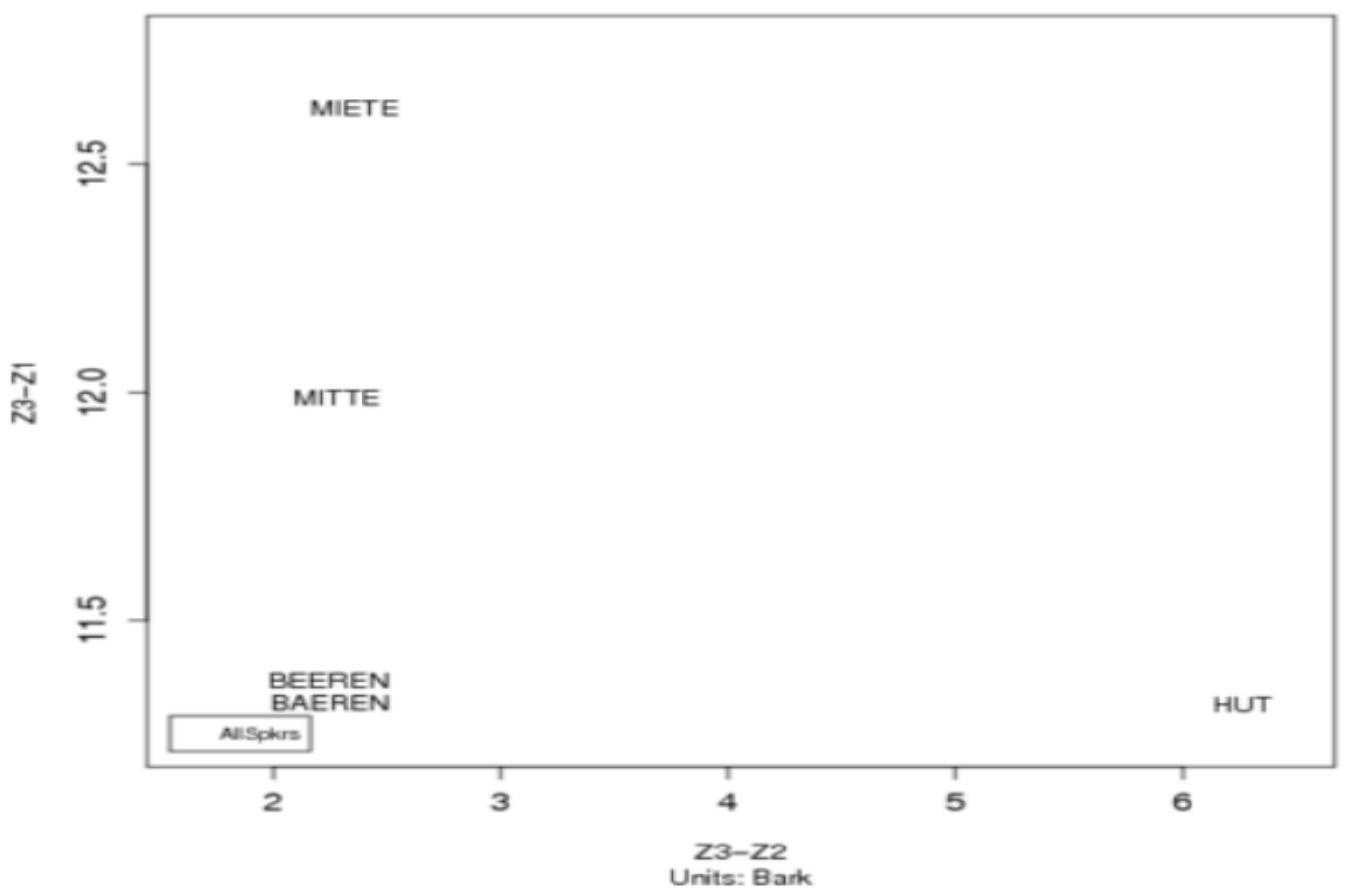


The most remarkable difference between the older and younger speakers' realizations is that the younger speakers make a clear distinction between the MIETE and the MITTE vowels whereas the older speakers merge them. Whereas Table 1 and Figure 3 showed a small quantitative differentiation between these vowels, the qualitative difference turns out to be most prominent. The younger speakers differentiate by raising the MIETE and MITTE vowels (as compared to the older speakers) and by raising the MIETE vowel even more than the MITTE vowel (note the different scales of the y-axis). That is, the younger speakers disperse the front vowels in the vowel space more than the older speakers. Figure 4 also shows that these vowels are a bit more fronted in the younger speakers than in the older speakers. The BEEREN and the BÄREN vowels on the other hand are not very much different among both age groups. The younger speakers tend to produce the BÄREN vowel a little bit higher than the older speakers.

Since the MIETE and the MITTE vowels also have length as a distinctive feature, we investigated whether length compensates for loss of vowel quality distinction in tense-lax pairs in the older speakers. Therefore, we computed the mean duration for the four vowels for each speaker and performed a correlation test on the degree of merger (the Pillai score) and the mean duration. We tested the hypothesis that the degree of merger negatively correlates with vowel length, viz. mergers are compensated for by a distinction in vowel length. The correlation coefficient was 0.425 , but it was far from significant ( $p=0.577$ ). An analysis on the subgroup MIETE/MITTE vowel did not show a correlation either.

\section{Discussion}

Previous studies reported variable neutralization of the MIETE and MITTE vowels and the BEEREN/BÄREN merger in ASG. In accordance with studies on pragmatic linguistics on ASG (Muhr, 1995; Muhr, 2003) and pronunciation studies on Swiss Standard German (Hove, 2002, Sloos, To appear), we hypothesized that ASG vowels are subject to accommodation to NSG. We therefore investigated the degree of distinction between these vowels in spontaneous speech, and compared the pronunciation of younger and older speakers. We found that the younger speakers produce more distinction between the vowels than older speakers. Moreover, we showed that younger speakers exploit the vowel space more than older speakers, indicating that the vowels are subject to ongoing dispersion.

Does this ongoing dispersion support our hypothesis that younger speakers accommodate to NSG? ASG speakers in general use more acoustic overlap between the MIETE and MITTE vowels than NSG speakers, as shown by Cunha et al. (2013). NSG speakers also clearly distinguish the MIETE and BEEREN vowels. Finally, in NSG, the BÄREN vowel is less often merged with the BEEREN vowel than in ASG (see e.g. Sloos, To appear). So for all three 
mergers, the younger speakers have a more NSG-like pronunciation than the older speakers.

The question arises how younger Austrian speakers started to differentiate between the vowels that were previously merged. A simple answer cannot be provided, since many factors are likely to play a role in an 'unmerger' process. First, we have to realize the mergers were most likely not really a full mergers but at most a near-merger (Sloos 2013b). Even the BEEREN and BÄREN vowels, which were truly perceived as merged even among Austrian linguists, remained to be distinct in orthography (Sloos, 2013b). Moreover, they have different realizations in the local dialects: the BÄREN vowel is often realized as /a:/ as in, for instance, Šubrt (2010) on the Vienna dialect and Abraham (1971) on Montafon: Radl 'wheel.DIM' (NSG Rädchen) and war 'be.SUBJ' (NSG wär). So the phonemic distinctions between the vowels were probably continually reflected in the language in some way or another. Through language contact with NSG, the reversals can occur. In Sloos (To appear) it is argued that perceptual salience plays a role in this process as well. The NSG pronunciation as [ $\varepsilon$ :] will not go unnoticed since a short $[\varepsilon]$ also exists in ASG. If the BÄREN vowel is perceived as being different from the native variety (that is, as $[\varepsilon:]$ instead of [e:]), it is perceptually more salient, hence accommodated to-under the assumption that NSG is the prestige variety. Note that these considerations assume that social as well as orthographical information is accessible during lexical retrieval, which in turn requires that these are stored and connected to representations of the sounds. This favours episodic models of language processing in which there is room for modelling sociolinguistic factors, orthography, as well as their relation between each other. These models suggest that in most cases, in lexical retrieval, a clear representation of a sound exists. But in case of extensive variation, competition between different forms arises which inhibits selection. In that case, the speaker may also retrieve social information in order to arrive at the selection of the most appropriate form. In case a selection is still difficult to be made, the speaker may also rely on orthographical knowledge (see Hay et al. (2006) and Sloos (2013b) for further discussion).

Our research has of course some limitations. First, we did not include the front rounded vowels. Previous studies like Cunha et al. (2013) showed that the $/ \mathrm{y} /$ and $/ \mathrm{y} /$ may also be neutralized in ASG, but the vowels are relatively infrequent, and difficult to investigate in spontaneous speech. We leave this to future research, and hypothesize that these vowels may also be subject to accommodation to NSG. Second, a perception study would shed more light on how the speakers distinguish the mergers and reversals. 


\section{Conclusion}

In Austrian Standard German, the four unrounded front vowels are subject to ongoing dispersion. We attribute this pattern of change to language contact with Standard German, the overt prestige variety, and subsequent accommodation of younger speakers. Older speakers, maintained a relatively narrow use of the vowel space and a merger of the BEEREN/BÄREN vowel pair and the MieTE/MitTE vowel pair.

\section{Acknowledgements}

The data for this study have been made available to the first author by Stefan Kleiner of the Institut für deutsche Sprache in Mannheim, which is gratefully acknowledged. We would like to thank the audience of Tabudag 2013 (Groningen) and Grote Taaldag 2014 (Utrecht) for fruitful discussions and Jeroen van der Weijer and two anonymous reviewers for comments on previous versions of this article.

\section{References}

Abraham, W. (1971). Das Vokalsystem der Mundart des Montafons [The vowel system of the dialect of the Montafon]. Zeitschrift Für Dialektologie Und Linguistik. 38,1, 95-120.

Ammon, U. (1995). Die deutsche sprache in Deutschland, Österreich und der Schweiz: Das Problem der nationalen Varietäten [The German language in Germany, Austria and Switzerland: The problem of national varieties]. De Gruyter, Berlin \& New York.

Ammon, U. (1996). On comparing the centers of plurinational languages: The example of German. In Contributions to the Sociology of Language, M. Hellinger \& U. Ammon, Eds. 17-36. Berlin: Walter de Gruyter.

Boersma, P., \& Weenink, D. (2010). Praat: Doing phonetics by computer. (computer program).

Brinckmann, C., Kleiner, S., Knöbl, R., \& Berend, N. (2008). German today: An areally extensive corpus of spoken standard German. In Proceedings of the Sixth International Conference on Language Resources and Evaluation (Marrakech, Marocco). 3185-3191.

Clyne, M. (1991). German as a pluricentric language. In Pluricentral Languages. Differing Norms in Different Nations, M. Clyne, Ed. 117-148. Mouton de Gruyter, Berlin.

Cunha, C., Harrington, J., \& Hoole, P. (2013). A physiological analysis of the tense/lax vowel contrast in two varieties of German. 14th Annual Conference of the International Speech Communication Association INTERSPEECH 2013: Speech in Life Sciences and Human Societies. F. Bimbot, Ed. 325-329.

Ehrlich, K. (2010). Die Aussprache des österreichischen Standarddeutsch: Umfassende Sprech-und Sprachstandserhebung der österreichischen Orthoepie [The pronunciation of the Austrian Standard German: Comprehensive speech 
and language assessment of Austrian orthoepy]. Unpublished $\mathrm{PhD}$ thesis, Universität Wien.

Hall-Lew, L. (2010). Improved representation of variance in measures of vowel merger. In Proceedings of Meetings on Acoustics (Baltimore, Maryland). 127, 3, 060002-060012.

Hay, J., Nolan, A., \& Drager, K. (2006). From fush to feesh: Exemplar priming in speech perception. The Linguistic Review, 23,3, 351-379.

Hove, I. (2002). Die Aussprache der Standardsprache in der deutschen Schweiz [The pronunciation of standard language in German-speaking Switzerland]. Niemeyer, Tübingen.

Iivonen, A. K. (1987). Monophthonge des gehobenen Wienerdeutsch [Monophthongs of Vienna's upscale German]. Folia Linguistica, 21, 2-4, 293-336.

Kendall, T., \& Thomas, E. R. (2007). NORM: The vowel normalization and plotting suite (software http://ncslaap.lib.ncsu.edu/tools/norm/).

Mangold, M. (1994). Duden Aussprachewörterbuch [Duden pronunciation dictionary]. Duden Verlag, Mannheim.

Moosmüller, S. (2007). Vowels in standard Austrian German. Unpublished Habilitation dissertation, University of Vienna.

Moosmüller, S. (2008). Interaction of phonetics, phonology, and sociophonologyillustrated by the vowels of standard Austrian German. In Proceedings of the 2 nd ISCA Workshop on Experimental Linguistics, ExLing 2008 (Athens, Greece). 173-176.

Muhr, R. (1995). Zur sprachsituation in österreich und zum begriff "Standardsprache" in plurizentrischen Sprachen. Sprache und Identität in Österreich [To said situation in Austria and the concept "standard language" in pluricentric languages. Language and Identity in Austria]. In Österreichisches Deutsch. Linguistische, sozialpsychologische und sprach-politische Aspekte einer nationalen Variante des Deutschen [Austrian German. Linguistic, social psychology and language policy aspects of a national variant of German], R. Muhr, R. Schrodt \& P. Wiesinger, Eds, 75-110. Verlag Hölder-Pichler-Tempsky, Wien.

Muhr, R. (2003). Language change via satellite: The influence of German television broadcasting on Austrian German. Journal of Historical Pragmatics, 4, 1, 103 127.

Muhr, R. (2007). Österreichisches Aussprachewörterbuch und österrreichische Aussprachedatenbank [Austrian pronunciation dictionary and Austrian pronunciation database]. Peter Lang Verlag, Frankfurt am Main \& Wien.

Sloos, M. (2013a). Frequency and phonological grammar: An integrated approach. Evidence from German, Indonesian, and Japanese. PhD dissertation, University of Groningen.

Sloos, M. (2013b). The reversal of the BÄREN/BEEREN merger in Austrian Standard German. The Mental Lexicon (Special Issue: Phonological and Phonetic Considerations of Lexical Processing). G. Jarema \& G. Libben , Eds. 8, 3, 353371.

Sloos, Marjoleine. (To appear). Merger and reversal of the BÄREN and BEEREN vowels: The role of salience. Studia Linguistica.

Stearns, M. J., \& Voge, W. (1979). The contemporary pronunciation of long in Modern Standard German: A data-based, computer-assisted analysis. In Hamburger Phonetische Beiträge. Untersuchungen zur Phonetik und Linguistik [Hamburger Phonetic posts. Studies on the phonetics and linguistics]. Miszellen VI, J. Köster, Ed. 127-181. Helmut Buske Verlag, Hamburg. 
Šubrt, P. (2010). Wiener Dialekt [Viennese dialect]. Unpublished MA thesis, Masaryk University of Brünn.

Traunmüller, H. (1990). Analytical expressions for the tonotopic sensory scale. The Journal of the Acoustical Society of America, 88, 1, 97-100.

Trudgill, P. (2008). Native-speaker phonological models and the English lingua franca core. In Katarzyna Dziubalska-Kołaczyk, Joanna Przedlacka (eds). English Pronunciation Models: A Changing Scene. Linguistic Insights. Studies in Language and Communication 21. Bern/Berlin etc: Peter Lang.

Wiesinger, P. (1996). Das österreichische Deutsch als eine Varietät der deutschen Sprache [The Austrian German as a variety of the German language]. Die Unterrichtspraxis/Teaching German, 29, 2, 154-164. 
